\title{
Inhibition of Growth by Imidazol(on)e Propionic Acid: Evidence in vivo for Coordination of Histidine Catabolism with the Catabolism of Other Amino Acids
}

\author{
Barry R. Bochner* and Michael A. Savageau \\ Department of Microbiology, The University of Michigan, Ann Arbor, Michigan 48109, USA
}

Summary. Imidazole propionic acid (ipa), a gratuitous inducer of the histidine-utilization (hut) system in Salmonella typhimurium, inhibits the organism's growth on succinate minimal medium. Induction of the hut system is necessary, but not sufficient, to cause inhibition. A study of the ability of single amino acids to relieve ipa-restricted growth suggests that insufficient glutamate is the cause of slow growth. The inhibition of growth by imidazolone propionic acid (iopa), an intermediate in the catabolism of histidine to glutamate, is similar to that by ipa. Studies using 2, 3, 5-triphenyl tetrazolium chloride plates to examine amino acid catabolism suggest that accumulation of ipa or iopa leads to inactivation of aspartate aminotransferase (AAT). This interpretation is supported by studies of an Escherichia coli mutant lacking AAT. The mutant grows poorly on succinate minimal medium, and the poor growth is relieved by the same amino acids that relieve ipa- and iopa-restricted growth. These and other findings are discussed in terms of coordination of the histidine-utilization system with enzymatic activities involved in the catabolism of other amino acids.

\section{Introduction}

Imidazole propionic acid (ipa) is a gratuitous inducer of the histidine-utilization (hut) system in Salmonella typhimurium (Schlesinger and Magasanik, 1965). Presumably, it acts as an analogue of urocanic acid and inactivates the hut repressor protein (hutC gene product; see Fig. 1). Since the compound is not metabolized, we were surprised to find that under certain

* Present Address: Department of Biochemistry, University of California, Berkeley, California 94720, USA

For offprints contact: B.R. Bochner
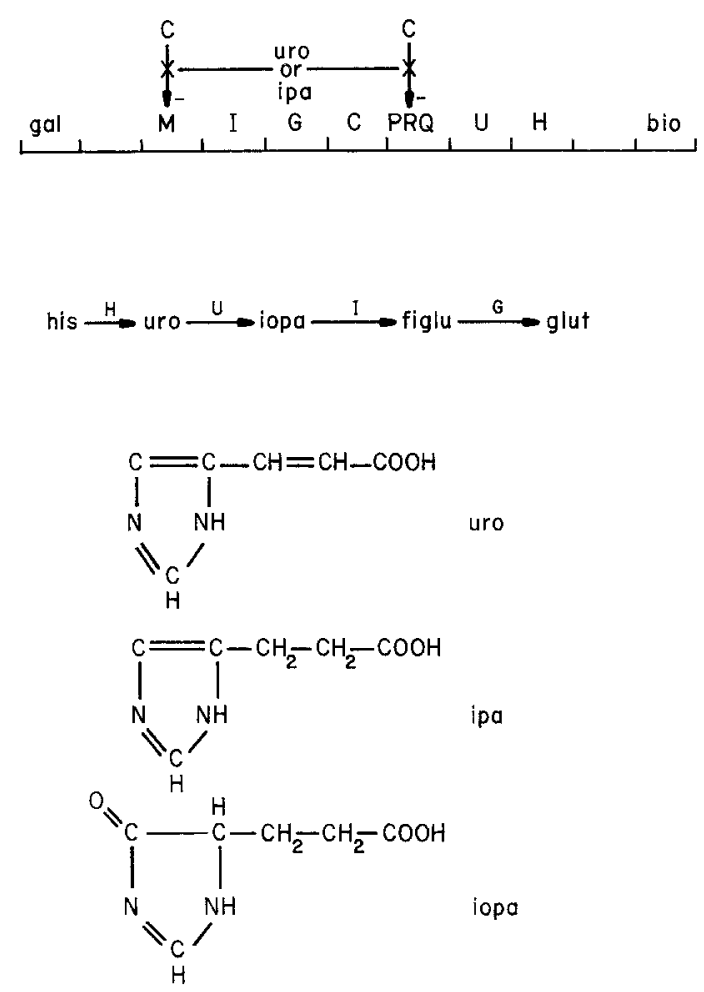

Fig. 1. The histidine utilization system of Salmonella typhimurium. The genes of the system are clustered in two operons. The first consists of the operator-promoter region $(m)$, the structural genes for the third $(I)$ and fourth $(G)$ enzymes in the pathway and the structural gene for the repressor protein $(C)$. The second operon consists of the operator-promoter region $(P R Q)$ and structural genes for the first $(H)$ and second $(U)$ enzymes of the pathway. The repressor binds to both operators and this binding is antagonized by the inducers urocanate (uro) and imidazole propionic acid (ipa). The intermediates in the conversion of histidine (his) to glutamate (glut) are: urocanate (uro), imidazolone propionic acid (iopa), and formiminoglutamate (figlu). The structures of the natural inducer uro and the analogues ipa and iopa are also given

conditions, ipa can inhibit the growth of $h u t^{+}$strains of S. typhimurium. Imidazolone propionic acid (iopa), an intermediate in the histidine catabolic pathway, 
has a structure similar to ipa and is also toxic to $S$. typhimurium. Though unstable and difficult to work with (Brown and Kies, 1959), iopa can be generated intracellularly in toxic quantities simply by adding histidine to hutI or hut $R$ mutant strains. In the first case, iopa is accumulated since it cannot be catabolized in the absence of the hutI gene product. In the second case, the hut $H$ and $U$ gene products are overproduced relative to the hutI gene product due to a mutation in the hut $R$ region (Hagen et al., 1975). The toxicity of iopa has been used to select for secondary mutations alleviating the growth inhibition. In addition to reversions of the original lesions, mutations in hut $H$, hut $U$, and hutR are classes that can be expected to prevent iopa accumulation and therefore toxicity. Two novel mutant classes have also been selected on the basis of iopa-resistance. One such mutant class consisted of lesions mapping in the hutC gene for the repressor protein (Hagen et al., 1975). A second class described recently consists of mutants that underproduce glutamine synthetase by virtue of lesions in $g \ln F$ (Gaillardin and Magasanik, 1978).

All of these mutants presumably alleviate iopa toxicity by diminishing iopa accumulation, the cause of growth inhibition. However, the reason for iopa toxicity has not been explored. In this paper we report on effects of ipa and iopa in vivo. Both compounds have quite similar effects, pleiotropically influencing the ability of amino acids other than histidine to be catabolized and thereby supply utilizable nitrogen to the cell.

\section{Materials and Methods}

\section{Bacterial Strains}

The strains used in this study are listed in Table 1. Since strain PV15 grows poorly on succinate minimal medium, its hutC lesion was cotransduced with the $\mathrm{gal}^{+}$genotype into strain BB4 to give strain BB47. Methods of transduction and procedures for selecting $\mathrm{gal}^{-}$mutants have been described previously (Bochner and Savageau, 1977). Strain BB99 was created by transducing strain BB22 to tetracycline resistance with phage grown on strain BB98. Transductants were selected on nutrient agar plates containing tetracycline $(25 \mu \mathrm{g} / \mathrm{ml})$.

Mutants incapable of degrading histidine $\left(h u t^{-}\right)$were obtained following two cycles of killing by ampicillin, or UV mutagenesis and one cycle. UV mutagenesis was performed by the method of Miller (1972). Ten ml of histidine minimal medium were inoculated with cells from an overnight culture to give a final concentration of $4 \times 10^{7}$ cells $/ \mathrm{ml}$. When growth was evident, $0.4 \mathrm{ml}$ of a fresh ampicillin solution $(2 \mathrm{mg} / \mathrm{ml})$ was added and incubation continued for about $90 \mathrm{~min}$. The cells were washed, resuspended in succinate minimal medium and incubated overnight. Cells from this overnight culture were spread ( 250 cells/plate) onto histidinesupplemented 2,3,5-triphenyl tetrazolium chloride (TTC) plates (Bochner and Savageau, 1977) and incubated 24 to $36 \mathrm{~h}$ at $37^{\circ} \mathrm{C}$. Putative mutants (Hut ${ }^{-}$colonies were white) were tested for their
Table 1. Strain list

\begin{tabular}{|c|c|c|}
\hline Name & Genotype & Source or derivation \\
\hline \multicolumn{3}{|c|}{ S. typhimurium LT2 } \\
\hline PV & Wild-type & $\begin{array}{l}\text { S. Weaver } \\
\text { (Meiss et al., 1969) }\end{array}$ \\
\hline PV3 & hutR49, hutM3 & $\begin{array}{l}\text { B. Magasanik } \\
\text { (Meiss et al., 1969) }\end{array}$ \\
\hline PV15 & hutR49, hutM3, hutC46, (?) & $\begin{array}{l}\text { B. Magasanik } \\
\text { (Meiss et al., 1969) }\end{array}$ \\
\hline BB4 & hutR49, hutM3, gal ${ }^{-}$ & $\begin{array}{l}\text { Spontaneous } \\
\text { mutant of PV3 }\end{array}$ \\
\hline BB11 & hutR49, hutM3, hutHI & $\begin{array}{l}\text { This laboratory } \\
\text { (Bochner and } \\
\text { Savageau, 1977) }\end{array}$ \\
\hline BB15 & hutR49, hutM3, hutU5 & UV mutagenesis of PV3 \\
\hline BB22 & hutR49, hutM3, hutII4 & $\begin{array}{l}\text { Spontaneous } \\
\text { mutant of PV3 }\end{array}$ \\
\hline BB37 & hutR49, hutM3, (?) & See text \\
\hline BB47 & hutR49, hutM3, hutC46 & $\begin{array}{l}\mathrm{Gal}^{+} \text {transduction from } \\
\text { PV15 into BB4 }\end{array}$ \\
\hline BB98 & putAB824::tn 10 & J. Roth \\
\hline BB99 & $\begin{array}{l}\text { hutR49, hutM3, hutII4, } \\
\text { putAB824:: } \operatorname{tn} 10\end{array}$ & $\begin{array}{l}\text { Tet }^{\mathrm{r}} \text { transduction from } \\
\text { BB98 into BB22 }\end{array}$ \\
\hline
\end{tabular}

E. coli $\mathrm{K}-12$

CS8 Hfr, $m e t^{-}, g l t C^{c},(\lambda) \quad$ G. Kohlhaw (Marcus and Halpern, 1969b)

CS8TA Hfr, $m e t^{-}, g l t \mathrm{C}^{\mathrm{c}}, a a t^{-},(\lambda) \quad$ G. Kohlhaw (Marcus and Halpern, 1969 b)

specific defect. hut $H$ mutants failed to grow on succinate + histidine, grew normally on succinate + urocanate, and lacked histidase activity. hut $U$ mutants grew slowly on succinate + histidine, failed to grow on succinate + urocanate, and lacked urocanase activity. hutI mutants grew slowly on succinate + histidine, failed to grow on succinate + urocanate, and were inhibited by histidine when grown on succinate + ammonium chloride.

\section{Growth-Rate Determinations}

The following method for growing cells gave reproducible growth rates and permitted simultaneous determinations on several cultures. An overnight culture was prepared by seeding $0.1 \mathrm{ml}$ of a stock culture in $10 \mathrm{ml}$ of fresh medium. After overnight incubation this culture was diluted to $10^{7}$ cells $/ \mathrm{ml}$ in a total volume of $10.5 \mathrm{ml}$. The cultures were grown in sterile, capped tubes $(25 \mathrm{~mm} \times 150 \mathrm{~mm}$ ) in a shaking-water bath (New Brunswick Model G76) at $37^{\circ}$ C. Growth was monitored turbidimetrically at $525 \mathrm{~nm}$ with a Fisher Electrophotometer (model II).

\section{Preparation of Extracts}

Each $10.5-\mathrm{ml}$ culture was harvested at a density of $10^{8}$ cells $/ \mathrm{ml}$ by centrifugation in the cold $\left(0-4^{\circ} \mathrm{C}\right)$ at $10,000 \mathrm{rpm}$ for $10 \mathrm{~min}$. The pellet was resuspended in $1 \mathrm{ml}$ of $10 \mathrm{mM}$ Tris- $\mathrm{HCl}(\mathrm{pH} 7.5)$, centrifuged again, and resuspended in $1 \mathrm{ml}$ of Tris- $\mathrm{HCl}$. These suspensions could be stored frozen for a day or two prior to sonic disruption and enzyme assay without loss of activity. Cells were sonically disrupted (Heat Systems - Ultrasonics, Inc., model W140, microtip, power setting 2.5) at $0-4^{\circ} \mathrm{C}$ for $1 \mathrm{~min}$. Cell debris was removed by centrifugation at $16,000 \mathrm{rpm}$ for $20 \mathrm{~min}$. The crude extracts typically had a protein concentration of $100 \mu \mathrm{g} / \mathrm{ml}$. 
Enzyme Assays

Enzyme activities were assayed spectrophotometrically at room temperature on a Gilford model 240 recording spectrophotometer. Quartz microcuvettes were used, and the total volume of each assay system was $0.8 \mathrm{ml}$. Absorbance as a function of time was not always linear initially, but within a few minutes it attained a constant rate of change that was assumed to reflect the true activity. A unit of activity is one nanomole of product formed per minute and specific activities are expressed as units per milligram of protein.

Histidase: This activity was assayed by measuring the increase in absorbance at $277 \mathrm{~nm}$ due to the formation of urocanic acid (molar extinction coefficient $=18,800$ ). The assay system, a modification of the method of Rechler and Tabor (1971), contained the following: $0.2 \mathrm{ml}$ of $500 \mathrm{mM}$ 2-amino-2-methyl-1,3-propanediol buffer ( $\mathrm{pH} 9.4), 0.1 \mathrm{ml}$ of $5 \mathrm{mM} \mathrm{MnCl}_{2}, 0.1 \mathrm{ml}$ of freshly prepared $140 \mathrm{mM} \beta$-mercaptoethanol, $0.2 \mathrm{ml}$ of cell extract, and $0.2 \mathrm{ml}$ of freshly prepared $100 \mathrm{mM}$ histidine ( $\mathrm{pH}$ 9.4).

Urocanase: Imidazolone propionic acid, the product of the urocanase reaction, reduces iodonitrotetrazolium (INT) via phenazine ethosulfate (PES). Thus, urocanase was assayed by following the increase in absorbance at $520 \mathrm{~nm}$ due to the formation of the INT-formazan (molar extinction coefficient $=11,800$ ). The assay system consisted of the following: $0.1 \mathrm{ml}$ of $1 \mathrm{M}$ potassium phosphate buffer ( $\mathrm{pH} 8.0$ ), $0.1 \mathrm{ml}$ of $0.2 \%$ gelatin, $0.1 \mathrm{ml}$ of $1 \mathrm{mM}$ PES, $0.1 \mathrm{ml}$ of $5 \mathrm{mM}$ INT, $0.1 \mathrm{ml}$ of neutralized $10 \mathrm{mM}$ ethylene diamine tetraacetate (EDTA), $0.2 \mathrm{ml}$ of cell extract, and $0.1 \mathrm{ml}$ of freshly prepared $1 \mathrm{mM}$ urocanic acid. Solutions of gelatin, PES, and INT were stored at $4^{\circ} \mathrm{C}$ in brown bottles.

Aspartate aminotransferase: This activity was assayed by measuring the increase in absorbance at $265 \mathrm{~nm}$ due to the formation of oxaloacetate (molar extinction coefficient $=780$ ). A modification of the assay system of Collier and Kohlhaw (1972) was used: $0.1 \mathrm{ml}$ of $1 \mathrm{M}$ potassium phosphate buffer $(\mathrm{pH} 8.0), 0.1 \mathrm{ml}$ of neutralized $10 \mathrm{mM}$ EDTA, $0.1 \mathrm{ml}$ of cell extract, $0.1 \mathrm{ml}$ of $100 \mathrm{mM}$ $\alpha$-ketoglutarate (sodium salt), and $0.1 \mathrm{ml}$ of $200 \mathrm{mM}$ aspartate (potassium salt). Sterile stock solutions of aspartate and $\alpha$-ketoglutarate were stored at $4^{\circ} \mathrm{C}$. Pyridoxal-5'-phosphate was omitted since it was found to be unnecessary. EDTA was added to prevent metal ions from altering the absorbance of the oxaloacetate formed (Harvey and Collins, 1963). A control cuvette lacking $\alpha$-ketoglutarate was run with each extract.

\section{Protein Determinations}

The protein content of cell extracts was determined by the method of Lowry et al. (1951) with bovine serum albumin (Sigma Chemical Co.) dissolved in Tris- $\mathrm{HCl}(2 \mathrm{mM}, \mathrm{pH} 7.5)$ as standard. The crude extracts, which also contained Tris- $\mathrm{HCl}(10 \mathrm{mM}, \mathrm{pH} 7.5)$, were diluted 5-fold and assayed in duplicate in disposable test tubes.

\section{Histidase Induction and Growth Inhibition}

by Imidazole Propionic Acid

For precise determination of growth rates, the optical densities of samples from a culture were read at $525 \mathrm{~nm}$ on a Zeiss Model PMQII Spectrophotometer. An overnight culture was diluted in $200 \mathrm{ml}$ of succinate minimal medium to a density of $6 \times 10^{6} \mathrm{cells} / \mathrm{ml}$. After growth to a density of $2 \times 10^{7}$ cells $/ \mathrm{ml}$, the culture was divided into two parts and imidazole propionic acid (ipa) was added to one giving a final concentration of $0.35 \%$. Every $15 \mathrm{~min}$ the optical densities of the two cultures were measured and a $10-\mathrm{ml}$ sample of the culture containing ipa was withdrawn and immediately vortexed with $1 \mathrm{ml}$ of cold $0.22 \%$ chloramphenicol. All samples were kept on ice until sampling was completed. Extracts were prepared and histidase activity assayed as previously described.
Relief of Poor Growth on Succinate

To measure the relief of ipa-restricted growth, an overnight culture of strain PV3 was diluted into fresh succinate minimal medium containing ipa $(0.35 \%)$ and single amino acids $(1 \mathrm{mM})$. Relief is expressed as a percent with that produced by proline defined as 100\% (actual doubling time: $55 \mathrm{~min}$ ) and that for a culture without any amino acid addition defined as $0 \%$ (actual doubling time: $110 \mathrm{~min}$ ). A culture with neither ipa nor amino acid had a doubling time of $63 \mathrm{~min}$.

To measure the relief of imidazolone propionic acid (iopa)restricted growth, an overnight culture of strain BB22 was diluted into fresh succinate minimal medium plus single amino acids ( $4 \mathrm{mM}$, except tyrosine $-2 \mathrm{mM}$ ). After one doubling, histidine ( $0.2 \%$ final concentration) was added to all but one culture. Relief is expressed as a percentage, with that produced by proline defined as $100 \%$ (actual doubling time: $68 \mathrm{~min}$ ) and that for the culture without any amino acid addition defined as $0 \%$ (actual doubling time: $220 \mathrm{~min}$ ). The culture with neither histidine nor any amino acid had a doubling time of $58 \mathrm{~min}$.

To measure the relief of restricted growth in the $a a t^{-}$strain (CS8TA), $0.1 \mathrm{ml}$ of a nutrient broth culture was diluted into fresh succinate minimal medium containing methionine $(0.5 \mathrm{mM})$ plus single amino acids $(4 \mathrm{mM})$. Doubling times were estimated between 10 and $20 \mathrm{~h}$ after inoculation. The relief produced by proline was defined as 100\% (actual doubling time: $80 \mathrm{~min}$ ) and that for a culture with methionine $(4 \mathrm{mM}$ ) was defined as $0 \%$ (actual doubling time: $564 \mathrm{~min}$ ). The addition of other amino acids shown as giving $0 \%$ relief actually resulted in slower growth than did the addition of methionine. A culture of the aat $^{+}$strain, CS8, without relieving amino acids had a doubling time of $100 \mathrm{~min}$.

To measure the relief of restricted growth in strain BB37, an overnight culture grown in succinate minimal medium supplemented with glutamine $(1 \mathrm{mM})$ was diluted into fresh succinate minimal medium plus single amino acids ( $4 \mathrm{mM}$, except tyrosine$2 \mathrm{mM}$ ). Relief is expressed as a percent, with that produced by proline defined as $100 \%$ (actual doubling time: $95 \mathrm{~min}$ ) and that for the culture without any amino acid addition defined as $0 \%$ (actual doubling time: $720 \mathrm{~min}$ ).

\section{Synthesis of Imidazole Propionic Acid}

The procedure used is based on the method of Kraml and Bouthillier (1955). $10 \mathrm{~g}$ of urocanic acid was dissolved in $1 \mathrm{~L}$ of distilled water containing $6 \mathrm{ml}$ of $12 \mathrm{~N} \mathrm{HCl}$. One $\mathrm{g}$ of palladium on powdered charcoal ( $5 \%$ catalyst) was added and the mixture stirred under one atmosphere of hydrogen in an apparatus made available through the generosity of the Department of Chemistry, The University of Michigan. The urocanic acid was quantitatively reduced to imidazole propionic acid. Reduction was complete within $24 \mathrm{~h}$ as judged by the uptake of 1 mmole of $\mathrm{H}_{2}$ per mmole of urocanic acid. The palladium catalyst was removed by filtering the solution through Celite (diatomaceous earth) and filter paper in a buchner funnel. Most of the water was evaporated by heating, and the hot concentrated solution was poured into a large glass petri dish containing a thin layer of acetone to obtain crystals.

Our preparation of ipa was somewhat unstable, its toxicity diminishing with a half-life of roughly six months. Since it is even more unstable in aqueous solution, freshly prepared and neutralized $1 \%$ stock solutions usually were used.

\section{Chemicals and Media}

Most of the chemicals and media used have been described previously, as have the methods of sterilization (Bochner and Savageau, 1977). 


\section{Results}

Imidazole propionic acid (ipa) inhibits the growth of $\mathrm{Hut}^{+}$strains of $S$. typhimurium growing in succinate minimal medium. For example, Fig. 2 shows that when ipa $(0.35 \%)$ is added to an exponentially growing culture of strain PV3, growth continues normally for about $45 \mathrm{~min}$, but then suddenly slows.

Several lines of evidence indicate that ipa toxicity is related to induction of the hut system. 1) A strain of S. typhimurium (PV) with an uninducible hut system, is not inhibited by ipa under identical conditions (Fig. 2). 2) Ipa is toxic to strain PV3 when the culture is grown in minimal medium with a carbon source permitting high levels of hut induction (e.g., succinate or malate) but not with a carbon source that restricts hut induction (e.g., glucose, galactose, lactate, glycerol, rhamnose, ribose, citrate, or adenosine). 3) The minimum inhibitory concentration of ipa with succinate-grown cells is about $0.1 \%$. The steady-state level of histidase (a measure of hut expression) under these threshhold conditions is 60 units per $\mathrm{mg}$ of protein. Higher concentrations of ipa induce higher levels of hut expression and restrict growth more severely (see Fig. 3). 4) As shown in Fig. 4, the onset of growth restriction occurs when the histidase activity has risen to 60 units per $\mathrm{mg}$ of protein. This is in agreement with the inhibitory threshhold of 60 units per mg of protein in steady state.

Although hut induction seems to be necessary for ipa-restricted growth, it does not reduce the growth rate per se. Strain PV3 grows normally when hut ex-

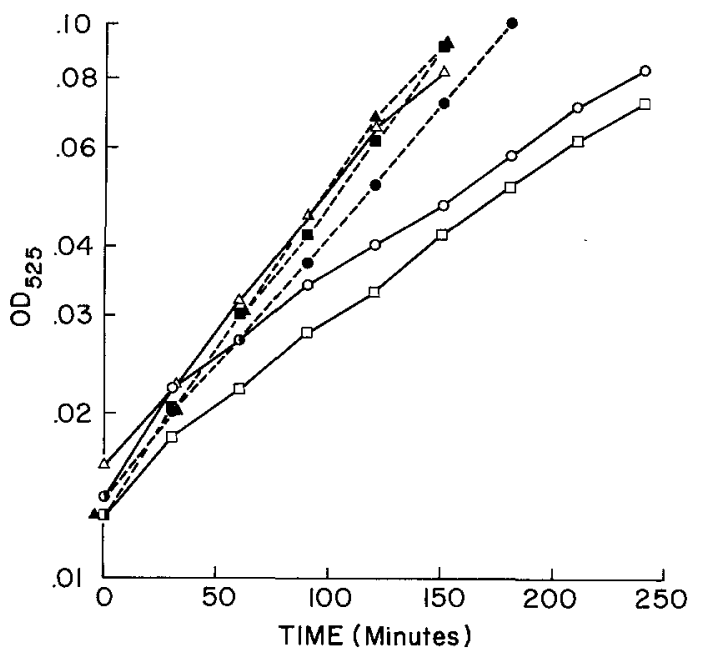

Fig. 2. The effect of ipa and iopa on the growth of several strains of S. typhimurium. Overnight cultures were diluted into fresh succinate minimal medium with or without additions, and growth was followed as described in Materials and Methods. Symbols: • strain PV3, no additions; 0 , strain PV3, $+0.35 \%$ ipa; $\mathbf{A}$, strain $\mathrm{PV}$, no additions; $\triangle$, strain PV, $+0.35 \%$ ipa; $\mathbf{m}$, strain BB22, no additions; $\square$, strain $B 22,+0.2 \%$ histidine

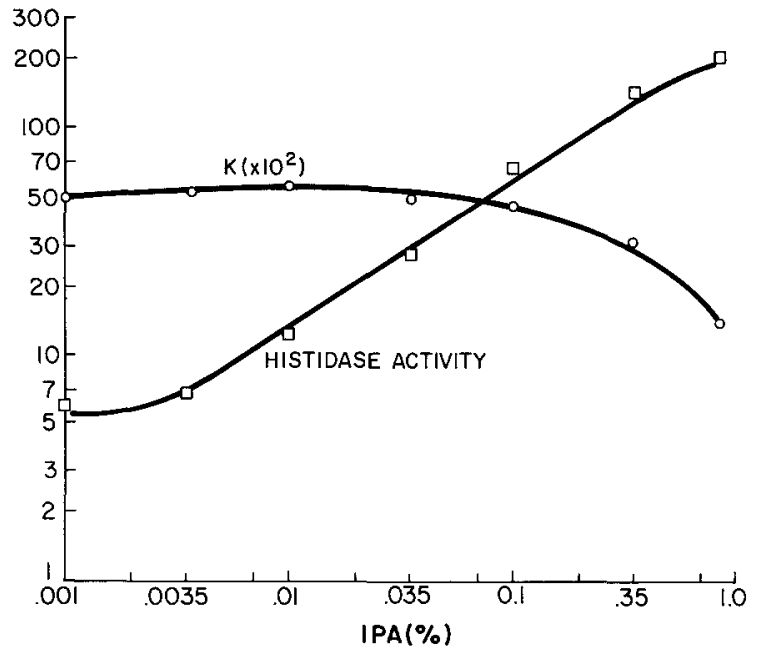

Fig. 3. Histidase level and growth rate of $S$. typhimurium strain PV3 versus concentration of ipa. The cells were allowed to reach a steady-state rate of growth in succinate minimal medium with the indicated concentrations of ipa. Symbols: $\square$, specific activity of histidase; $O$, rate of growth in terms of the constant $\mathrm{K} \times 10^{2}$ ( $\mathrm{K}=\ln 2 /$ doubling time in hours)

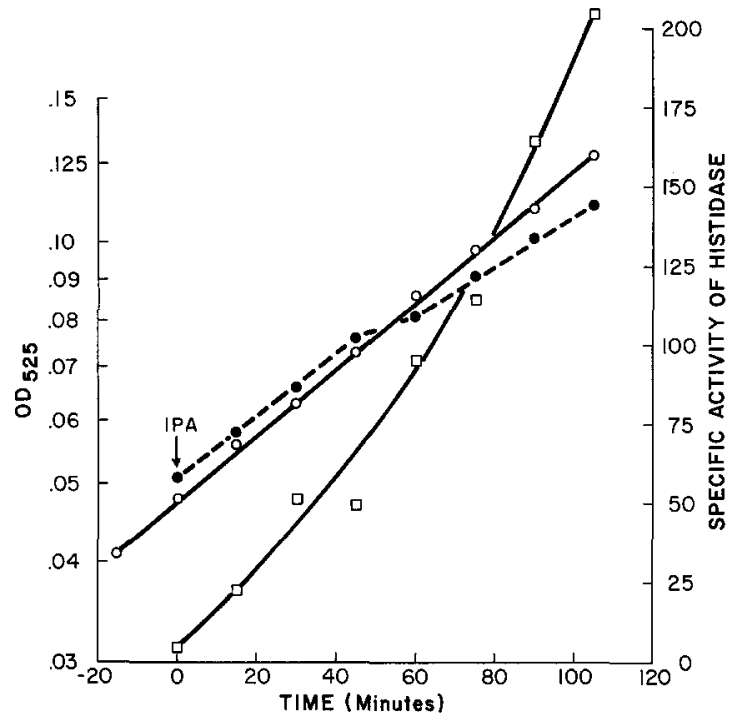

Fig. 4. Kinetics of ipa-restricted growth and histidase induction in S. typhimurium strain PV3. At the time indicated ipa was added to one of two identical cultures growing on succinate minimal medium. Symbols: 0 , optical density of culture with no ipa; $\bullet$, optical density of culture with $0.35 \%$ ipa; $\square$, specific activity of histidase in the culture containing ipa

pression is induced by histidine or urocanate, the natural inducer. Moreover, constitutive hutC (BB47) and hut $U$ (BB15) mutants grow at the same rate as their parent strain on succinate minimal medium. In an attempt to identify the component of the hut system that mediates ipa toxicity, we tested the hut $H,-U$, $-I$, and $-C$ mutants listed in Table 1 to see if any of these exhibits altered ipa sensitivity. However, all strains were indistinguishable from their parent in this respect. 
To characterize the deficit in ipa-restricted cells, we tested the ability of individual amino acids to relieve the restriction. The results of this survey, combined with previous results from other laboratories, are summarized in the first four columns of Table 2. We made several tentative conclusions from these data: 1) Various amino acids are capable of relieving ipa-restricted growth to different extents. Thus, ipa cannot be simply inhibiting an enzyme in an amino acid biosynthetic pathway. Furthermore the pattern of relief observed does not resemble the groupings of amino acids that share transport systems (Halpern, 1974). Relief cannot be readily explained in terms of competitive inhibition of ipa uptake. 2) Relief of ipa-restricted growth by an amino acid correlates well with its ability to be used as a nitrogen source. To serve as a nitrogen source, an amino acid must readily donate amino groups to glutamate. Thus, restriction of growth by ipa appears to result from a depletion of the internal glutamate pool. Glutamate itself is not the best reliever, probably because it is transported poorly into the cell (Brenchley et al., 1975; Marcus and Halpern, 1969a). 3) Amino acids that interact with the glutamate pool via a transaminase cannot serve as nitrogen sources and are poor relievers of ipa-restricted growth. Those that do not interact via transamination can serve as nitrogen sources and are good relievers. 4) Aspartate is an obvious exception to the general patterns observed. More will be made of this later.

Since ipa-restricted growth seems to require both the presence of ipa and hut induction, it is conceivable that amino acids could "relieve" ipa-restricted growth by somehow blocking hut induction. To test this we measured the level of hut expression in cultures simultaneously provided with ipa and other amino acids. We found in fact that the degree to which an amino acid was effective in reversing ipa-toxicity paralleled its effectiveness in lowering hut expression. For example, the histidase level in cells grown in succinate minimal medium plus ipa $(0.35 \%)$ is 131 units. The addition of $(1 \mathrm{mM})$ tryptophan lowers this to 112 , glutamine to 76 , alanine to 57 , and proline to 38 . However, studies on proline reversal of ioparestricted growth (described in the next section) lead us to believe that amino acids turn down hut expression to the extent by which they can supply amino groups for glutamate synthesis. We propose, in other words, that the lowering of hut expression may be a coincident effect rather than a cause of growth stimulation.

\section{Restriction of Growth by Iopa}

Magasanik and his colleagues previously observed that the growth rates of S. typhimurim (Hagen et al.,
Table 2. The ability of amino acids to relieve the poor growth of various strains on succinate

\begin{tabular}{|c|c|c|c|c|c|c|}
\hline \multirow[t]{2}{*}{$\begin{array}{l}\text { Amino } \\
\text { acid }\end{array}$} & \multirow[t]{2}{*}{$C / N^{b}$} & \multirow[t]{2}{*}{$\mathrm{TA}^{\mathrm{c}}$} & \multicolumn{4}{|c|}{$\begin{array}{l}\% \text { relief of growth-rate restriction } \\
\text { due to }\end{array}$} \\
\hline & & & $\begin{array}{l}\text { ipa } \\
\text { (PV3) }\end{array}$ & $\begin{array}{l}\text { iopa } \\
\text { (BB22) }\end{array}$ & $\begin{array}{l}\text { aat } \\
\text { lesion } \\
\text { (CS8TA) }\end{array}$ & $\begin{array}{l}\text { Unknown } \\
\text { lesion } \\
\text { (BB37) }\end{array}$ \\
\hline pro & $\mathrm{CN}$ & - & 100 & 100 & 100 & 100 \\
\hline ala & $\mathrm{CN}$ & - & 86 & 0 & 96 & 84 \\
\hline ser & $\mathrm{CN}$ & - & 86 & 60 & 0 & 84 \\
\hline his & $\mathrm{CN}$ & - & 61 & $-{ }^{\mathrm{d}}$ & 25 & 70 \\
\hline$g \ln$ & $\mathrm{N}$ & - & 60 & 60 & 88 & 58 \\
\hline glt & $\mathrm{N}$ & - & 40 & 68 & 100 & 42 \\
\hline asn & $\mathrm{N}$ & - & 45 & 58 & 54 & 58 \\
\hline gly & $N$ & - & 30 & 50 & 59 & 65 \\
\hline thr & - & - & 32 & 47 & 54 & 70 \\
\hline $\arg$ & $\mathrm{N}$ & - & 15 & 47 & 32 & 54 \\
\hline lys & - & $?$ & 14 & 47 & 22 & 36 \\
\hline met & - & TAT & 8 & 74 & 0 & 0 \\
\hline $\operatorname{trp}$ & - & TAT & 0 & 84 & $\ldots^{e}$ & 0 \\
\hline phe & - & TAT & 27 & 79 & 0 & 0 \\
\hline tyr & - & TAT & 18 & 65 & $-^{e}$ & 7 \\
\hline val & - & B & 9 & 0 & 0 & 47 \\
\hline ile & - & B & 7 & 0 & 0 & 43 \\
\hline leu & - & B & 0 & 0 & 0 & 30 \\
\hline asp & $\mathrm{CN}$ & AAT & 3 & 8 & 0 & 0 \\
\hline
\end{tabular}

See Materials and Methods for definition of \% relief

b Ability of amino acids to serve as the sole source of carbon (C) or nitrogen (N) or neither (-) for S. typhimurium LT2. Taken from the data of Gutnick et al. (1969)

c Existence of an enzyme that transaminates the amino acid with $\alpha$-ketoglutarate: no known transaminase $(-)$, tyrosine-repressible aromatic transaminase (TAT), branched-chain transaminase $B$ (B), aspartate aminotransferase (AAT). Based on the data of Rudman and Meister (1953) and Mavrides and Orr (1975)

d Since histidine was added to elicit iopa-restriction, it could not be tested for relief of restriction

e These were not tested

1975) and Klebsiella aerogenes (Goldberg and Magasanik, 1975) hutI mutants were reduced when histidine was added to their growth media. This restriction is due to the accumulation of iopa, the substrate of the hutI gene product (Hagen et al., 1975). Since ipa and iopa have similar structures, we suspected a similarity in their action. In fact, iopa-restriction of a hutI mutant growing on succinate minimal medium is a delayed phenomenon and results in a reduction of growth rate comparable to that observed with ipa (see Fig. 2).

The patterns for amino acid relief of ipa- and iopa-restricted growth (columns 4 and 5 in Table 2) are also quite similar with two major exceptions. The first is that methionine, tryptophan, phenylalanine, and tyrosine are good relievers of iopa-restricted growth but poor relievers of ipa-restricted growth. Since these four amino acids interact with the glutamate pool through a common transaminase (Chesne and Pelmont, 1973; Mavrides and Orr, 1974), it ap- 
Table 3. The effect of intermediates of the histidine catabolic sequence on the catabolism of amino acids by $S$. typhimurium judged on TTC plates

\begin{tabular}{|c|c|c|c|c|c|c|c|c|c|c|c|c|c|c|c|}
\hline \multirow[t]{3}{*}{ Strain } & \multirow{3}{*}{$\begin{array}{l}\text { hut } \\
\text { genotype }\end{array}$} & \multicolumn{14}{|c|}{ Test substrate } \\
\hline & & \multicolumn{2}{|c|}{ L-proline } & \multicolumn{2}{|c|}{ L-glutamate } & \multicolumn{2}{|c|}{ L-aspartate } & \multicolumn{2}{|c|}{ D-alanine } & \multicolumn{2}{|c|}{ L-alanine } & \multicolumn{2}{|c|}{$\mathrm{D}$-serine } & \multicolumn{2}{|c|}{ L-serine } \\
\hline & & - & + his & - & + his & - & this & - & + his & - & + his & - & this & - & + his \\
\hline PV3 & $h u t^{+}$ & $\mathrm{R}$ & $\mathrm{R}$ & $\mathrm{R}$ & $\mathrm{R}$ & $\mathrm{R}$ & $\mathrm{R}$ & $\mathrm{R}$ & $\mathrm{R}$ & $\mathrm{R}$ & $\mathrm{R}$ & SR & $\mathrm{R}$ & $\mathrm{R}$ & $\mathrm{R}$ \\
\hline BB47 & hutC & $\mathrm{R}$ & $\mathrm{R}$ & $\mathrm{R}$ & $\mathrm{R}$ & $\mathrm{R}$ & $\mathrm{R}$ & $\mathrm{R}$ & $\mathrm{R}$ & $\mathrm{R}$ & $\mathrm{R}$ & SR & $\mathrm{R}$ & $\mathrm{R}$ & $\mathrm{R}$ \\
\hline BB11 & hut $H$ & $\mathrm{R}$ & $\mathrm{R}$ & $\mathrm{R}$ & $\mathrm{R}$ & $\mathrm{R}$ & $\mathrm{R}$ & $\mathrm{R}$ & $\mathrm{R}$ & $\mathrm{R}$ & $\mathrm{R}$ & $\mathrm{R}$ & $\mathrm{R}$ & $\mathrm{R}$ & $\mathrm{R}$ \\
\hline BB 15 & hutU & $\mathrm{R}$ & $\mathrm{R}$ & $\mathrm{R}$ & $\mathrm{SR}$ & $\mathrm{R}$ & $\mathrm{R}$ & $\mathrm{R}$ & $\mathrm{R}$ & $\mathrm{R}$ & $\mathrm{R}$ & $\mathrm{R}$ & $\mathrm{R}$ & $\mathrm{R}$ & $\mathrm{R}$ \\
\hline BB22 & hutI & $\mathrm{R}$ & $\mathrm{SR}$ & $\mathrm{R}$ & W & $\mathrm{R}$ & IR & $\mathrm{R}$ & IR & $\mathrm{R}$ & IR & $\mathrm{R}$ & $\mathrm{R}$ & $\mathrm{R}$ & $\mathrm{R}$ \\
\hline BB37 & $h u t^{+}$ & SR & $\mathrm{R}$ & W & IR & IR & SR & IR & $\mathrm{SR}$ & $\mathrm{R}$ & $\mathrm{R}$ & SR & $\mathrm{R}$ & $\mathrm{R}$ & $\mathrm{R}$ \\
\hline
\end{tabular}

The six S. typhimurium strains were streaked on sectored TTC plates and incubated at $37^{\circ} \mathrm{C}$ for $48 \mathrm{~h}$. TTC reduction by colonies of the six strains was periodically assessed. The rate at which the test substrate is utilized correlates with the rate and/or extent of colony coloration (Bochner and Savageau, 1977). Colony coloration is coded above as: white (W), incompletely red (IR), slowly red (SR) and normally red (R). The amino acids were used as test substrates at a concentration of $0.5 \%$ except for L-glutamate, which was $1.0 \%$. The effect of accumulation of intermediates in histidine catabolism was tested by adding histidine $(0.2 \%)$ to the plates

pears that the activity of this trnasaminase in vivo is affected differently by ipa and iopa. Alanine, the second exception, is a good reliever of ipa-restricted growth but a poor reliever of iopa-restricted growth. Here again, ipa and iopa appear to have different effects on the transfer of an amino group, in this instance from alanine to $\alpha$-ketoglutarate.

In the cases of both ipa- and iopa-restricted growth, aspartate is a very poor reliever. At the other end of the spectrum, proline is the most effective reliever. However, proline is not able to relieve ioparestricted growth in an isogenic strain defective in proline catabolism. Strain BB99 has normal permease activity $\left(\right.$ put $\left.\mathrm{P}^{+}\right)$and put induction but lacks the enzymatic activities required to convert proline to glutamate. This finding supports our contention that ioparestricted growth results from a glutamate limitation, and that the ability of proline to relieve this limitation is by virtue of its ability to be converted to glutamate. An indirect effect of proline is unlikely.

\section{Identification of the Site of Action of Ipa and Iopa}

Ipa or iopa could cause a glutamate limitation by 1) decreasing glutamate synthesis or 2) increasing glutamate degradation. We examined enzymes involved in glutamate synthesis (GDH and GOGAT) and found no evidence for repression or inhibition of either. Next, we employed tetrazolium plates as a simple and direct way to detect stimulation of glutamate degradation by iopa in vivo. The rate at which colonies turn red on a glutamate-TTC plate is an indication of the rate at which they catabolize glutamate (Bochner and Savageau, 1977). Strain PV3 and strains deri- ved from it, take 2 days to turn red on a glutamateTTC plate at $37^{\circ} \mathrm{C}$. If iopa stimulates glutamate breakdown, then addition of histidine to a glutamateTTC plate should cause a hutI mutant (accumulating iopa) to turn red faster, but should not affect a hutH mutant (accumulating histidine) or a hut $U$ mutant (accumulating urocanate). This prediction was tested, and the results are shown in Table 3. Contrary to our expectations, iopa completely blocked glutamate degradation.

Marcus and Halpern (1969 b) have published evidence indicating that glutamate catabolism is mediated by aspartate aminotransferase (AAT). If iopa accumulation leads to "inactivation" of AAT, this would 1) explain why aspartate was unable to relieve iopa- and ipa-restricted growth (Table 2), and 2) suggest that catabolism of other amino acids utilizing AAT also might be slowed by iopa. To test this prediction, the hutI mutant and several control strains were streaked on TTC plates containing an amino acid test substrate with and without the addition of histidine. As shown in Table 3, iopa accumulation did slow the breakdown of $\mathrm{L}$-aspartate and L-proline, which are probably catabolized, at least in part, via AAT. Breakdown of D- and L-alanine also was slowed in the presence of iopa. These amino acids probably are not catabolized via AAT, but reduction of their catabolism by iopa is once again in accord with the inability of L-alanine to relieve iopa-restricted growth (Table 2). As before, hutH and hutU mutants served as controls in these studies, and their catabolism of amino acids was unaffected by the addition of histidine. Furthermore, the catabolism of D- and L-serine and D,L-malate (data not shown) was not affected by iopa accumulation in the hutI mutant, demonstrating the specificity of the effect. 
Growth Properties of an

E. coli Mutant Lacking AAT

Our experiments with ipa and iopa suggest that both compounds cause depletion of the internal glutamate pool in succinate-grown cells and reduction of AAT activity in vivo. Both of these findings could be explained by postulating that AAT functions in glutamate synthesis when cells are growing in succinate minimal medium. However, the limited evidence available from glucose-grown cells indicates that AAT functions in aspartate synthesis (Gelfand and Steinberg, 1977) and is not able to supply amino groups for glutamate (Berberich, 1972; Brenchley and Magasanik, 1974).

A simple test of our postulate is to see whether a mutant lacking AAT is deficient for aspartate or glutamate in succinate minimal medium. Although no one has reported the isolation of a S. typhimurium mutant lacking AAT, such a mutant has been isolated in the closely related species E. coli (Marcus and Halpern, 1969b). We obtained this mutant, strain CS8TA, along with its parent, strain CS8, and compared their growth with glucose or succinate as sole carbon source. On glucose minimal medium the mutant and its parent had identical doubling times (62 min). On succinate minimal medium, however, the mutant grew poorly compared with its parent. The pattern of relief by single amino acids for strain CS8TA was quite similar to that seen for iparestricted $S$. typhimurium (see Table 2), again suggesting a glutamate limitation. The exceptions to this pattern, serine, histidine, and glutamate, are to be expected since strain CS8TA is sensitive to $\mathrm{L}$-serine (Cosloy and McFall, 1970; Bochner, unpublished data), $h u t^{-}$, and carries a mutation $\left(g l t \mathrm{C}^{\mathrm{c}}\right)$ permitting rapid transport of glutamate.

\section{Growth Properties of Strain BB37}

Another S. typhimurium mutant, strain BB37 provides additional relevant information. While its origin is uncertain, it was labeled PV4, indicating a mutant lacking histidase activity (Meiss et al., 1969), in a shipment of strains from Magasanik's laboratory. Although we have been unable to trace its origin further (B. Magasanik, personal communication), it appears to be closely related to strain PV3. Strain BB37 has several interesting characteristics. Its growth properties resemble those of the E. coli aat ${ }^{-}$mutant. Strain BB37 grows normally on glucose but poorly on succinate. Growth on succinate is stimulated by the same amino acids that do so for the aat mutant, with the exception of the branched-chain ones (see Ta- ble 2). The data in Table 3 indicate that strain BB37 is defective in catabolizing glutamate and aspartate and bears a striking resemblance to the iopa-restricted hutI mutant. Strain BB37 does have AAT activity as measured by our assay, however, and probably is not mutated in the structural gene for this enzyme.

\section{Discussion}

In $\mathrm{Hut}^{+}$strains of $S$. typhimurium, histidine is catabolized via three intermediates to glutamate. When ipa or iopa accumulates in cells in which the hut operon is induced, growth inhibition ensues after a $20-45 \mathrm{~min}$ delay. Studies of the reversal of growth inhibition indicate that the cells are starved for glutamate. Iopa is the second intermediate in the histidine catabolic sequence, and since iopa accumulation leads to a glutamate starvation, we are led to believe that iopa may be part of a signalling system for nitrogen flow. Iopa signals the cell to expect a supply of glutamate from histidine. The cell responds by curtailing other routes of glutamate synthesis. When no glutamate is produced, a starvation results.

The interaction between the hut system and amino group transfer that we have observed may not be unique. The proline utilization ( $p u t$ ) system is similar to the hut system in function and regulation (Dendinger and Brill, 1970). Dendinger and Brill (1972) have found that baikiain, a gratuitous inducer of the put system and an analogue of proline and $\Delta^{\prime}$-pyrroline-5carboxylate, can restrict the growth of $\mathrm{Put}^{+}$strains of $S$. typhimurium. This inhibition required induction of the put enzymes and was maximized when the cells were grown in succinate minimal medium. Baikiain-resistant mutants were selected and found to be pleiotropically negative for the enzymes of the put system. Two out of three of these mutations were $100 \%$ cotransduced with putC. This is similar to the iopa-resistant mutant isolated by Hagen et al. (1975): the mutation produced super repression of the hut enzymes and was mapped within the hutC gene.

If ipa- or iopa-restricted cells are harvested and sonicated, they have normal high levels of aspartate aminotransferase activity as measured by the assay described in the methods section (unpublished results). Yet, all of our data suggest that this enzyme is catalytically inactive in ipa- and iopa-restricted cells: (1) Aspartate, normally a good nitrogen source, is not able to relieve the glutamate deficit in ipa- or ioparestricted cells. (2) Iopa accumulation blocks glutamate degradation which proceeds via AAT. (3) Iopa accumulation slows aspartate and proline degradation which also presumably would utilize AAT. (4) Ipaand iopa-restricted cells have growth properties that 
are strikingly similar to an E. coli strain lacking AAT.

Several lines of evidence suggest that the "inactivation" of AAT which follows ipa and iopa accumulation is an indirect consequence: (1) While iopa and especially ipa would be expected to accumulate rapidly in cells, growth restriction sets in after a 20-45 min delay. (2) Ipa-restriction seems to require hut induction as well as the presence of ipa. (3) Ipa does not inhibit AAT activity in our assay at concentrations up to $1.0 \%$ (unpublished data). (4) S. typhimurium strain BB37 closely resembles the E. coli aat ${ }^{-}$ strain and iopa-inhibited cells, yet crude extracts of this strain clearly have AAT activity. (5) Previous genetic evidence suggests that more than one protein is involved in determining the activity of AAT in vivo. A new mutant of $E$. coli lacking AAT activity has been isolated and mapped (Gelfand and Steinberg, 1977; Gelfand and Rudo, 1977). The locus involved, aspC, is about $40 \%$ cotransducible with serC at 20 min on the E. coli chromosome. However, cotransduction of the aat lesion in strain CS8TA (identical to strain YM8111) with $\operatorname{ser} C$ could not be demonstrated (Gelfand and Rudo, 1977). (6) Ioparestriction affects the catabolism of $\mathrm{D}$ - and L-alanine and the aromatic amino acids as well as aspartate. This pleiotropy also suggests the collaboration of one or more other proteins. All of these observations lead us to postulate that i(o)pa has as a target, a cellular protein capable of affecting the in vivo activity of other amino acid catabolizing enzymes. The $g \ln F$ gene product and glutamine synthetase are two possible target proteins. Some lesions causing iopa-resistance are linked to $g \ln F$ and others to $g \ln A$ (Gaillardin and Magasanik, 1978).

Though iopa accumulation has pleitropic consequences, the growth inhibition observed may be attributed to one of its sites of action - the "inactivation" of AAT. If cells growing in succinate minimal medium assimilate some of their nitrogen into aspartate, and then transfer the nitrogen via ATT onto $\alpha$-ketoglutarate, inactivation of AAT would lead to a glutamate starvation. Likewise, mutants lacking AAT would be starved for glutamate when grown in succinate minimal medium. Growth of these mutants would be stimulated by glutamate-producing amino acids, but not by aspartate. Evidence obtained thus far supports these interpretations.

Succinate minimal medium typically allows the highest levels of induction of amino acid catabolic enzymes in enterobacteria. This observation has been rationalized in terms of stimulation of transcription of these genes by the cAMP system. cAMP levels are high in succinate-grown cells. However, we would like to suggest a different interpretation that also is consistent with the available data.
Strains of $S$. typhimurium and E. coli seem to have difficulty accumulating sufficient levels of glutamate when growing on C4-dicarboxylic acids. As already described (Straus and Hoffman, 1975), the descendants of the original LT2 strain differ in their ability to grow on C4-dicarboxylic acids as the sole source of carbon. Many LT2 strains form colonies of various sizes when streaked on succinate or malate minimal plates. We have found that these strains grow better and produce more uniform colonies if glutamine replaces ammonia as the nitrogen source. Even the PV strains that normally grow well on these carbon sources grow better when proline is provided. Thus, the high level of induction of amino acid catabolic enzymes may be due to low intracellular glutamate.

Acknowledgments. The authors are grateful to E. Juni for many helpful discussions and to A.M. Kotre for critically reading the manuscript.

This investigation was supported in part by Institutional Research Grant No. IN-40-0 to the University of Michigan from the American Cancer Society and a grant from the National Science Foundation (BMS 75-01591). B.R.B. was a Predoctoral Trainee in the Bioengineering Program supported by Public Health Service grant GMO 1289 from the National Institute of General Medical Sciences.

\section{References}

Berberich, M.A. : A glutamate-dependent phenotype in E. coli K12: the result of two mutations. Biochem. Biophys. Res. Commun. 47, 1498-1503 (1972)

Bochner, B.R., Savageau, M.A.: A generalized indicator plate for genetic, metabolic, and taxonomics studies with microorganisms. Appl. Environ. Microbiol. 33, 434-444 (1977)

Brenchley, J.E., Baker, C.A., Patil, L.G. : Regulation of the ammonia assimilatory enzymes in Salmonella typhimurium. J. Bacteriol. 124, 182-189 (1975)

Brenchley, J.E., Magasanik, B.: Mutants of Klebsiella aerogenes lacking glutamate dehydrogenase. J. Bacteriol. 117, 544-550 (1974)

Brown, D.D., Kies, M.W.: The mammalian metabolism of L-histidine. J. Biol. Chem. 234, 3188-3191 (1959)

Chesne, S., Pelmont, J.: Glutamate-oxalacétate transaminase d'Escherichia coli: I- purification et spécificité. Biochimie 55, 237-244 (1973)

Collier, R.H., Kohlhaw, G.: Nonidentity of the aspartate and aromatic aminotransferase components of transaminase $\mathrm{A}$ in Escherichia coli. J. Bacteriol. 112, 365-371 (1972)

Cosloy, S.D., McFall, E.: L-serine-sensitive mutants of Escherichia coli K-12. J. Bacteriol. 103, 840-841 (1970)

Dendinger, S., Brill, W.J.: Regulation of proline degradation in Salmonella typhimurium. J. Bacteriol. 103, 144-152 (1970)

Dendinger, S., Brill, W.J. : Effect of the proline analogue baikiain on proline metabolism in Salmonella typhimurium. J. Bacteriol. 112, 1134-1141 (1972)

Gaillardin, C.M., Magasanik, B.: Involvement of the product of the $g \ln F$ gene in the autogenous regulation of glutamine synthetase formation in Klebsiella aerogenes. J. Bacteriol. 133, 1329-1338 (1978) 
Gelfand, D.H., Rudo, N.: Mapping of the aspartate and aromatic aminotransferase genes $\operatorname{tyr} B$ and $a s p C$. J. Bacteriol. 130, 441-444 (1977)

Gelfand, D.H., Steinberg, R.A. : Escherichia coli mutants deficient in the aspartate and aromatic amino acid aminotransferases. J. Bacteriol. 130, 429-440 (1977)

Goldberg, R.B., Magasanik, B.: Gene order of the histidine utilization (hut) operons in Klebsiella aerogenes. J. Bacteriol. 122, 1025-1031 (1975)

Gutnick, D., Calvo, J.M., Klopotowski, T., Ames, B.N.: Compounds that serve as the sole source of carbon or nitrogen for Salmonella typhimurium LT-2. J. Bacteriol. 100, 215-219 (1969)

Hagen, D.C., Gerson, S.L., Magasanik, B.: Isolation of superrepressor mutants in the histidine utilization system of Salmonella typhimurium. J. Bacteriol. 121, 583-593 (1975)

Halpern, Y.S.: Genetics of amino acid transport in bacteria. Annu. Rev. Genet. 8, 103-133 (1974)

Harvey, R.J., Collins, E.B.: The citritase of Streptococcus diacetilactis. J. Biol. Chem. 238, 2648-2653 (1963)

Kraml, M., Bouthillier, L.P.: The conversion of urocanic acid to glutamic acid in the intact rat. Can. J. Biochem. Physiol. 33, 590-598 (1955)

Lowry, O.H., Rosebrough, N.J., Farr, A.L., Randall, R.J. : Protein measurement with the Folin phenol reagent. J. Biol. Chem. 193, 265-275 (1951)

Marcus, M., Halpern, Y.S.: Genetic analysis of the glutamate permease in Escherichia coli K-12. J. Bacteriol. 97, 1118-1128 (1969a)

Marcus, M., Halpern, Y.S.: The metabolic pathway of glutamate in Escherichia coli K-12. Biochim. Biophys. Acta 177, 314-320 (1969b)
Mavrides, C., Orr, W.: Multiple forms of plurispecific aromatic: 2-oxoglutarate (oxalacetate) aminotransferase (transaminase A) in Escherichia coli and selective repression by L-tyrosine. Biochim. Biophys. Acta 336, 70-78 (1974)

Mavrides, C., Orr, W.: Multispecific aspartate and aromatic amino acid transaminases in Escherichia coli. J. Biol. Chem. 250, 4128-4133 (1975)

Meiss, H.K., Brill, W.J., Magasanik, B.: Genetic control of histidine degradation in Salmonella typhimurium, strain LT-2. J. Biol. Chem. 244, 5382-5391 (1969)

Miller, J.H. : Experiments in molecular genetics. Cold Spring Harbor: Cold Spring Harbor Laboratory, 1972

Rechler, M.M., Tabor, H.: Histidine ammonia-lyase (Pseudomonas), (149a), pp. 63-69 (1971). In: Methods in enzymology (S.P. Colowick and N.O. Kaplan, eds.), Vol. XVII B (H. Tabor and C.W. Tabor, eds.), Metabolism of amino acids and amines. New York: Academic Press, Inc., 1971

Rudman, D., Meister, A.: Transamination in Escherichia coli. J. Biol. Chem. 200, 591-604 (1953)

Schlesinger, S., Magasanik, B.: Imidazolepropionate, a nonmetabolizable inducer for the histidine-degrading enzymes in Aerobacter aerogenes. J. Biol. Chem. 240, 4325-4330 (1965)

Straus, D.S., Hoffman, G.R.: Selection for a large genetic duplication in Salmonella typhimurium. Genetics 80, 227-237 (1975)

Communicated by G. O'Donovan

Received July 17, 1978 